\title{
ORÍGENES DEL TOPÓNIMO RÍO DE ORO
}

\author{
Francisco Narváez López \\ Profesor tutor de Derecho Internacional Público \\ del Centro UNED Melilla
}

Resumen: Este trabajo realiza una aproximación a los orígenes del topónimo río de Oro a través del estudio de la cartografía histórica, libros de geografía, documentos oficiales, literatura, prensa escrita, etc. Igualmente se aborda el uso del topónimo Uad el Meduar y sus variantes en Marruecos. Ambos se refieren al mismo río, pero en un espacio distinto, es decir, a su paso por Marruecos y Melilla. Los dos hidrónimos tienen un origen diferente. El nombre de Uad el Meduar enumera o hace referencia a unas de las características físicas más relevante del río, es decir, a sus meandros. Por el contrario, el origen del nombre de río de Oro hay que buscarlo en las leyendas que hacían referencia a su riqueza aurífera, algo que nunca se ha demostrado y que ha pervivido entre nosotros hasta bien entrado el siglo $\mathrm{XX}$, atrayendo a estos lugares a buscadores de oro y fortuna.

Palabras clave: Toponimia, río, oro, meduar, Marruecos, Melilla.

Abstract: This work is an approach to the origin of the place-name of the Gold River through the study of historical cartography, geography books, official documents, literature, press news and so on. At the same time, we deal with the use of the name Uad El Meduar and its variations in Morocco. Both of them refer to the same river but in a different place, that is, depending on if the river goes through Morocco or through Melilla. The two names have a different origin. The name of Uad el Meduar refers to some of the most relevant physical characteristics of the river, its meanders. On the contrary, the origin of the name Gold River" can be found in the legends that make reference to its gold wealth, something that has never been proved and that has been living with us until the end of the XX century, attracting to these places gold prospectors and fortune hunters.

Keywords: Place names, river, gold, Morocco, Melilla.

Una aproximación histórica al topónimo del río que atraviesa Melilla obliga a distinguir entre las denominaciones que recibe o ha recibido en $\mathrm{Ma}$ rruecos y en España, dado que no hay coincidencia entre los nombres de uno y otro lado. 
En esta tarea surgen varios problemas. El primero es que existen pocos documentos marroquíes sobre el nombre y no coinciden con las referencias orales rifeñas que ha recogido la bibliografía española. El segundo es que los documentos españoles (planos, mapas, cartas, libros, artículos, descripciones, monografías, etc.) utilizan nombres variados para designar este mismo punto en Marruecos y en España, con transcripciones variopintas del topónimo tamazight a la lengua española.

Para empezar, al acercarnos al nombre del río a su paso por Beni Chikar y Mazuza, hay que tener en cuenta que los rifeños para designar un lugar concreto suelen utilizar topónimos que describen o enumeran algunas de sus características, de tal manera que el nombre por sí solo permite su identificación, incluso para los extraños, por resaltar algún aspecto físico, material o espiritual del lugar que designan. Ahora bien, la descripción de río en las fuentes orales rifeñas no son coincidentes, variando su denominación (arroyo de Idoudouhane, río de Hidoun, Igsar o Igzar Izaruren, el río, Igzar Rmduar, Ulad Meduar, Uad El Meduar, río de Mariguari, río de Beni Chikar, etc.) según el tramo del cauce ante el que nos encontremos y, además, el objeto definido no siempre coincide con la realidad física que los melillenses conocemos como río de Oro, pues en ocasiones se utiliza el nombre para referirse a todo el río, a una parte del mismo o a un arroyo o gran barranco que le sirve de afluente. Un ejemplo lo cita Vicente Moga ${ }^{1}$ : "el nacimiento del río, se conoce como «Igzar Imrabden» o río de los morabitos (santos bereberes), denotando quizá el topónimo con que los pobladores de los aduares vecinos, denominan al Monte Gurugú, en el que nace, y que llaman «Sidi Hamed el Hadj», nombre del morabito o marabut que está enterrado, y tiene su morabo, en una de las cimas de este sistema montañoso”.

El mismo autor nos dice que a su paso por Farhana el río se conoce como rmduar. Así lo llamaban los rifeños desde hacía siglos y le seguirían

\footnotetext{
${ }^{1}$ MOGA ROMERO, Vicente, "Melilla \& las plazas menores (Chafarinas; Vélez de la Gomera; Alhucemas) en el «Diccionario Geográfico-Estadístico-Histórico de España y sus posesiones de ultramar» (Madrid, 1845-1850) de Pascual Madoz", Aldaba, Revista del Centro Asociado de la UNED de Melilla, nº.9,1987, p. 219.
} 
llamando hoy en día, a partir del giro brusco que realiza a los pies de Irgerman donde su pendiente se suaviza, pues con el nombre de "Ulad Meduar" se le describe en un interesantísimo trabajo sobre la "Cabila de Beni Sicar" (sin editar) realizado sobre 1925 por la Policía Indígena. Con el nombre de "Denduar” es citado en 1722 por Nicolás Vázquez en su descripción ${ }^{2}$ de "Benichicar", cuando dice "pasa por este lugar el río de Oro, llamado por los moros Denduar, que después de discurrir por el campo y fertilizar su vega, desemboca al suroeste de la Plaza de Melilla como a tiro de fusil de la misma”. También es citado como "El Meduar” por Gabriel de Morales en su libro Efemérides y Curiosidades. Melilla, Peñón y Alhucemas.

Todas estas denominaciones (Denduar, el Igsar Rmduar, Uad Meduar, Uad Medduar, etc.) no son más que diferentes trascripciones a la grafía latina del topónimo rifeño que viene a significar "el que serpentea, el que rodea, el que describe un círculo".

Una de las características de los ríos con pendientes muy escasas es la aparición de los meandros, es decir, de curvas descritas por el curso del río, de tal manera que el cauce desciende serpenteando hacia el mar. Y ésta es precisamente la característica más evidente del Igzar o Uad El Meduar, o como se quiera o deba transcribir al castellano, hasta el punto que tampoco es desacertada su traducción como río de los meandros ${ }^{3}$, río que serpentea o río sinuoso.

En una ocasión también se le ha llamado río Guajujar, nombre que vemos en un grabado de la revista El Mundo Militar ${ }^{4}$ de 1862, que reproduce con detalle los elementos más significativos de las edificaciones de Melilla y de su campo exterior ${ }^{5}$. Esta denominación podría ser una transcripción libre de "ouad harhar", formada a partir de la palabra árabe "wad" (río) y la rifeña "aharhar" (murmullo) es decir "el río de los murmullos" posiblemente rela-

2 VÁZQUEZ, Nicolás, "Descripción de la Provincia de Alcalaya”, Servicio Histórico Militar (SHM), sig. (0-7-95), Melilla, 1722, p. 4-5-7-4, fol. 13v., citado por SÁEZ CAZORLA, Jesús Miguel, "El Puerto de Melilla y sus instalaciones: de la edad media hasta mediados del siglo XVIII", El Puerto de Melilla, 2009, BRAVO NIETO, Antonio; Juan Antonio BELLVER GARRIDO, p. 48.

3 SARO GANDARILlAS, Francisco, "Casi un río: el río de Oro", Estudios Melillenses, 1996, Ciudad Autónoma de Melilla, pp. 224-231.

4 “Vista General de Melilla”, El Mundo Militar, de 30 de marzo de 1862, nº. 125, p. 100. 
cionada con otra expresión popular rifeña como es “aharhar waman”, el murmullo del agua, pero referida al murmullo causado por el viento al mover las cañas que crecían en sus márgenes.Y Francisco Coello ${ }^{6}$ en su Reseña general de el Rif nos dice que el río del Oro "se compone de varios arroyuelos, siendo los principales el Frajana y el Xart Umasín, que es el más extenso y desciende del SSO”. Este "Xart Umasín” se correspondería con el río de Oro, no siendo fácil buscar una traducción aceptable en castellano, lo que demuestra, una vez más, lo poco rigurosas ${ }^{7}$ que eran las transcripciones españolas de los accidentes geográficos rifeños ${ }^{8}[1]$.

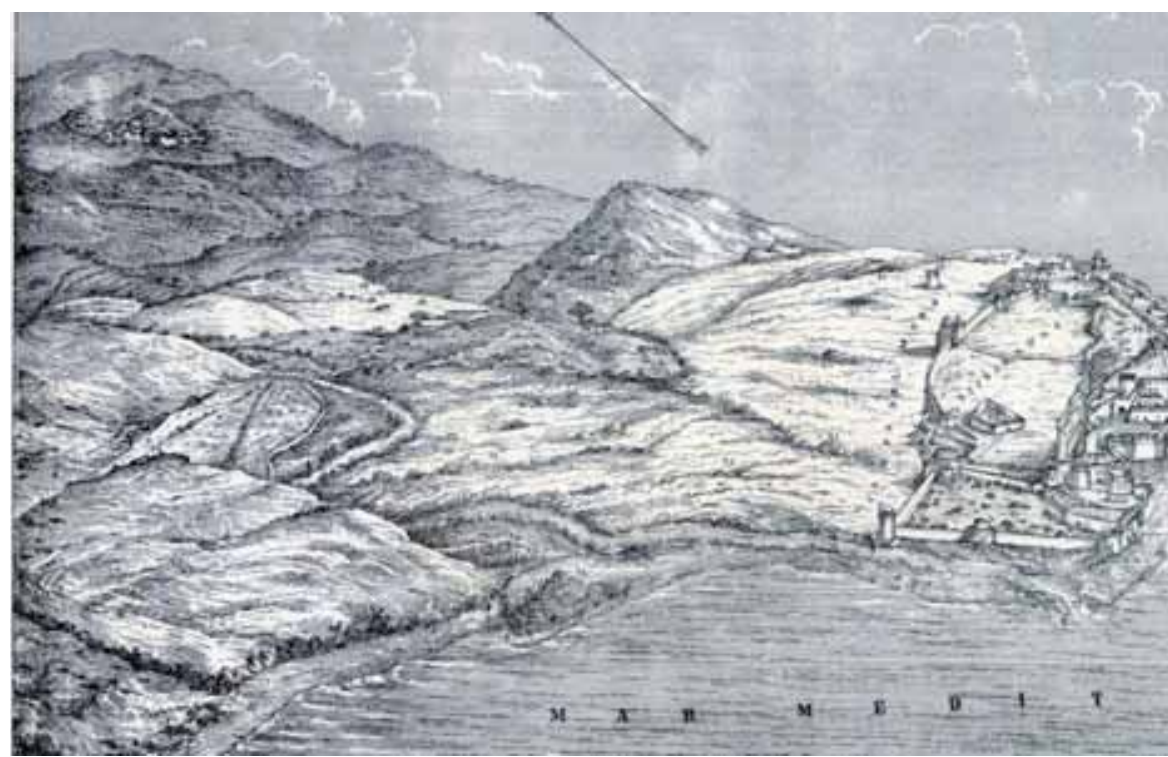

Fig. 1. Sector de una litografía de Francisco Rojo, Vista de la parte del SO. de la plaza y Campo de Melilla, 1850-862.

${ }^{5}$ El grabado es idéntico a la litografía de Francisco Rojo, Vista de la parte del SO. de la plaza y Campo de Melilla, Madrid, SGE, D.L. 1992.

${ }^{6}$ COELLO, Francisco, “Reseña general de el Rif”, Revista de Geografía Comercial, 1894, nº 125 128 , p. 8 .

${ }^{7}$ MARTÍNEZ YAGUES, F, “El Árabe y el Xelja. La rotulación de los planos”, Revista África Española, tomo IV, Agosto-diciembre 1914, nº. 21, pp. 567-570.

${ }^{8}$ Uad ed Dehah, es denominado en el Mapa del Norte de Marruecos, 1945, Hoja 7, Melilla, SGE, S.P, $n^{\circ}$. 1.569. Ver en: http://bibliotecavirtualdefensa.es (7-01-2016). 
La cartografía y documentos españoles usarán para identificar al río una denominación propia, alejándose u omitiendo las rifeñas ${ }^{9}$. Según Gabriel de Morales $^{10}$, en los planos antiguos y de principios de la Edad Moderna el río no tenía ningún nombre y en los documentos "más próximos a la época de la conquista lo llamaban sencillamente el Río o río de Melilla y esta misma denominación la empleaban los libros parroquiales", quizá porque el río no tuvo la importancia militar y sanitaria que tendría años más tarde y , no había necesidad de llamarle de una forma determinada ${ }^{11}$. En las décadas siguientes recibiría diversos nombres, llamándose "río de Melilla" en el plano descrito como Sitio de Melilla, de autor desconocido, realizado entre 1774 y 1775 [2].

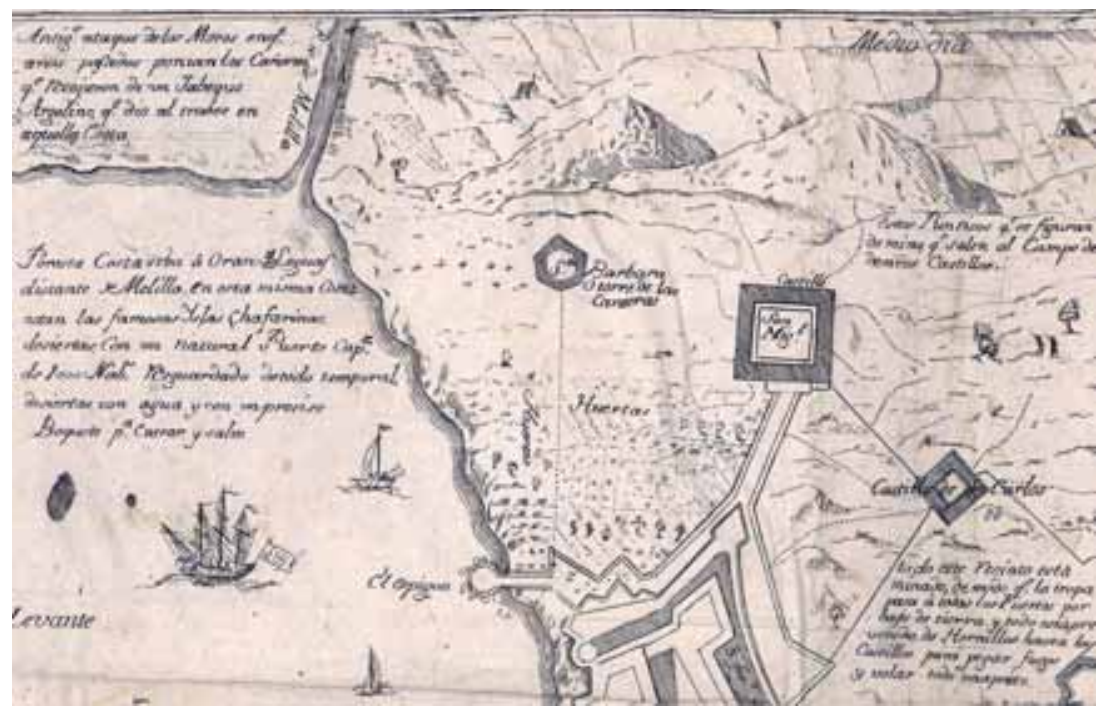

Fig. 2. Sector de un plano del Sitio de Melilla, 1774-1775.

${ }^{9}$ Son pocos los planos españoles en los que se recogen las denominaciones españolas y rifeñas (Río Mduar y Río de Oro), entre ellos destaca el Croquis de Guelaya, tomado de planos levantados por Ingenieros militares, Estado Mayor y Dirección Facultativa de la Junta de Obras del Puerto, Memoria de la Junta de Fomento de Melilla, 1911, Imprenta: El Telegrama de Melilla, 1911.

${ }^{10}$ DE MORALES Y MENDICUTÍA, Gabriel, Efemérides y Curiosidades. Melilla, Peñón y Alhucemas, Melilla, 1921, pp. 294-296.

${ }^{11}$ Archivo General de Simancas (AGS): Plano de la Plaza de Melilla como está en principio de diciembre de 1695, signatura: MPD, 62,047; Plano de la Plaza de Melilla como está en principio de febrero de 1699, Alfonso Díez de Aux, signatura: MPD, 10, 164; Melilla con sus attaques, 1715, Sansom Des Allois, signatura: MPD, 54,010; Plano la Plaza y Presidio de Melilla del año 1722, signatura: MPD, 
Gabriel de Morales $^{12}$ nos dice que en alguna ocasión se le cita como río de la Olla: "en las vísperas del Sor. San Juan, a los 23 de Junio del dicho año de 644, a la una de la modorra comenzó a llover, creciendo por instantes el agua como hasta las once del día, salió el Río que llaman la Olla hacia (aquí una palabra que parece "majucar") del fuerte de San Marcos y todo aquel pago de viñas y huertos derribó las tapias, rompió bardos, taló árboles, enteró unas cepas y descubrió las raíces de otras, llevose a la mar la mies que estaba por trillar junto a las palmas de la vega.... "Este nombre lo vemos usado por vez primera en una descripción de la plaza y del campo que en 1677 enviaba el alcaide D. José Frías a S.M., descripción a la cual acompañaba un plano, que, desgraciadamente, se ha perdido; pero aún después de esta fecha se siguió empleando algunas veces el nombre de río de la Olla”.

Según de Morales $^{13}$, como en la vega de Melilla no había otro que mereciera ese nombre, le parece evidente que sólo del río Oro se podía tratar. Ahora bien, no compartimos esta conclusión, pues como pone de manifiesto Rodríguez Puget ${ }^{14}$ una Hoya, Olla u Oya es un barranco, en este caso identificable con el barranco del Polígono o de la Olla donde se situaba la celada llamada el Arroyo Seco de las Ramblillas. En época de fuertes lluvias el agua de escorrentía ${ }^{15}$ que venía de Rostrogordo por el barranco del Polígono (recogiendo las aguas de Cabrerizas, Tiro Nacional y Horcas Coloradas) se unía a las aguas de la Cañada y Ataque Seco, alcanzando un gran caudal que desembocaba cerca de los huertos ${ }^{16}$. Por otra parte, en esta época (me-

64, 013; Plano de la Plaza de Melilla situada en África, 1729-1732, Pedro Coisevaux, signatura: MPD, 59,065; Plano de la Plaza de Melilla con sus cercanías y campo inmediato, 1790, Segismundo Font, signatura: MPD, 08,228; Plano que manifiesta un pedazo de recinto de fortificación de la Plaza de Melilla, Muelle y porción de sus obras exteriores con la Magistral de la proyectada en la margen del Rio..., 1792, Joseph de Ampudia y Vallés, signatura: MPD, 65,011; Plano de una porción de frente de Melilla en la que se manifiesta el muelle, el fondeadero, Playa del Mantelete y el Río... de 1801-1802, signatura: MPD, 65, 011.

${ }^{12}$ DE MORALESY MENDICUTÍA, Gabriel, Efemérides de la Historia de Melilla (1497-1913), Centro Asociado de la UNED, Melilla, 1995, p. 53.

${ }^{13}$ DE MORALES, Efemérides y Curiosidades..., pp. 294-296.

${ }^{14}$ RODRIGUEZ PUGET, Joaquín, Crónicas de una fortificación. Siglos XVI-XVII, Melilla, Melilla, Carmelo Martínez S.L., 2001, pp. 201 y 305.

${ }^{15}$ La escorrentía es la lámina de agua que circula sobre la superficie en una cuenca de drenaje y es especialmente importante en suelos de zonas áridas y de precipitaciones torrenciales, como es el caso del río de Oro.

${ }^{16}$ En las crónicas del siglo XX se recoge en la prensa local cómo las aguas procedentes de estos 
diados del siglo XVII) el cauce y desembocadura del río de Oro se encontraban más alejados de las murallas, de modo que el río de la Olla debía ser el “arroyo" del Polígono.

Se le llamó "río de la Plata" en el mapa ${ }^{17}$ Territorio de Melilla que se conserva en el AHM del año 1692 o "río de Platta" en un plano ${ }^{18}$ de 1728 (¿) [3].

También se le menciona en el romance anónimo ${ }^{19}$ titulado Horrorosos Estragos, ocasionados por la Fiera Crupecia ${ }^{20}$ que apareció en Melilla en el Río de la Plata que Pío Baroja ${ }^{21}$, a juzgar por el grabado que encabezaba un romance, describe como " un monstruo femenino, con cuatro cuernos, alas de murciélago, dos patas y dos garras suplementarias a cada lado. Su voracidad era terrible. El hombre del cartel que vendía los romances, hombre, sin duda, de gran cultura histórica, aseguraba que la fiera comidamás que el animal llamado Heliogábalo...”.

Ahora bien, son los topónimos "río del Oro", "río Oro” y "río de Oro", los más usados en la cartografía, documentación histórica y en las obras descriptivas de la Plaza desde el siglo XVII en adelante. Estas variaciones referidas al Oro, se desarrollaron de la siguiente forma.

Río del Oro. Este nombre se empieza a generalizar a partir de mediados del siglo XVIII, cuando Juan Antonio Estrada ${ }^{22}$ escribe que a Melilla le incomoda "un río con arenas que arroja en haviendo mucha lluvia, llamado

barrancos terminaban convirtiéndose en un verdadero río, que alcanzaba en el Mantelete alturas superiores a un metro.

${ }^{17}$ Autor: Marcos Ayala.

${ }^{18}$ Plano de la Plaza de Melilla y sus contornos en el cual se ven los ataques de los moros y el proyecto de una línea para ocupar la altura de la Plaza de Melilla y del fuerte que se pretende executar, 1728, Juan de la Ferriere, AGS, signatura: MPD, 60, 052.

${ }^{19}$ Ver en: http:/ / bibliotecadigital.jcyl.es/i18n/consulta/registro. $\mathrm{cmd}$ ?id=8061(7-01-2016)

${ }^{20}$ En la mitología asturiana Crupecia es una bestia de extraño aspecto parecido a la quimera de la mitología griega, con cuerpo de harpía provisto de cuatro mamas, cola, boca de león y cuernos de toro. Este ser se dedica a asustar a los niños que encuentran por los bosques. Oir el romance en: https://www.youtube.com/watch?v=-OjBsnDuOTs (20-01-2016).

${ }^{21}$ BAROJA, Pío, "Carteles de Feria y literatura de Cordel”, Revista de información médico-terapéutica, XXII, nº. 21-22, 1947, pp. 1.024-1.033.

22 ESTRADA, Juan Antonio, Población general de España, sus reynos y provincias, ciudades, villas y pueblos, islas adjacentes, y presidios de Affrica, Madrid: Imprenta Mercurio, 1768, p. 491. 
del oro, por algunas pintas que suelen extraer las arenas con este precioso metal. La boca del río está a un tiro de mosquete de la plaza, y en su nacimiento sacan barro los moros para labrar ollas, cazuelas y otras maniobras, que salen con las referidas pintas. Son muy estimadas en España por su hechura y duración”. Esta cita es importante para entender el topónimo, primero porque es la primera vez que se explica su origen y, segundo, porque Juan Antonio Estrada era natural de Melilla, de modo que su testimonio tiene un valor especial y directo.

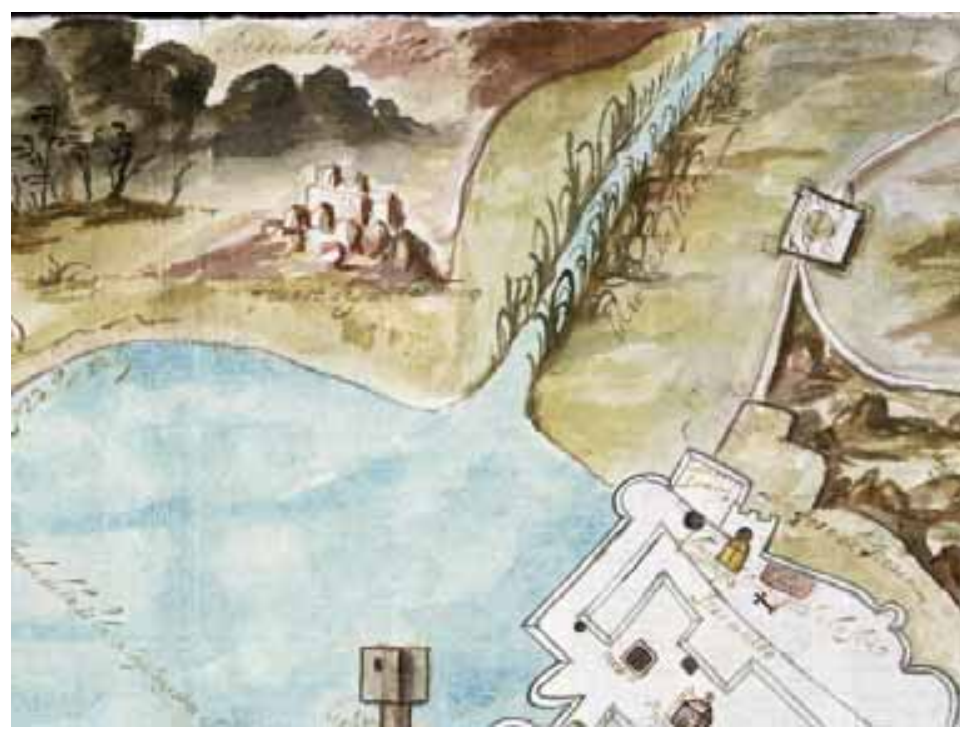

Fig. 3. Sector de un plano con la Planta de la fortificación y contornos de Melilla, 1692. AGS, signatura: MPD, 80, 253.

En 1792, en la Enciclopedia Metódica. Geografía Moderna ${ }^{23}$, se dice que a Melilla "le incomoda hacia allí la vecindad de un río con muchas arenas que arroja en tiempos de lluvia. Llámanle río del oro por las pajillas y granos de este rico metal que suelen arrastrar entre sus arenas". Otra obra, el Diccionario Geográfico-Estadístico-Histórico de España y sus posesiones de ultramar de Pascual Madoz ${ }^{24}$, afirma que "la vega de Melilla no es grande, pero

\footnotetext{
${ }^{23}$ Traducida del francés al castellano por Juan Arribas y Soria y Julián de Velasco, tomo tercero, Madrid, Imprenta de Sancha, 1792, pp. 112-113.

${ }^{24}$ MOGA, “Melilla \& las plazas menores...”, p. 201.
} 
pudiera ser deliciosa si los moros la cultivasen. Báñala un río de mediano caudal llamado del Oro que desemboca en el día muy cerca de las fortificaciones inferiores de la plaza" [4].

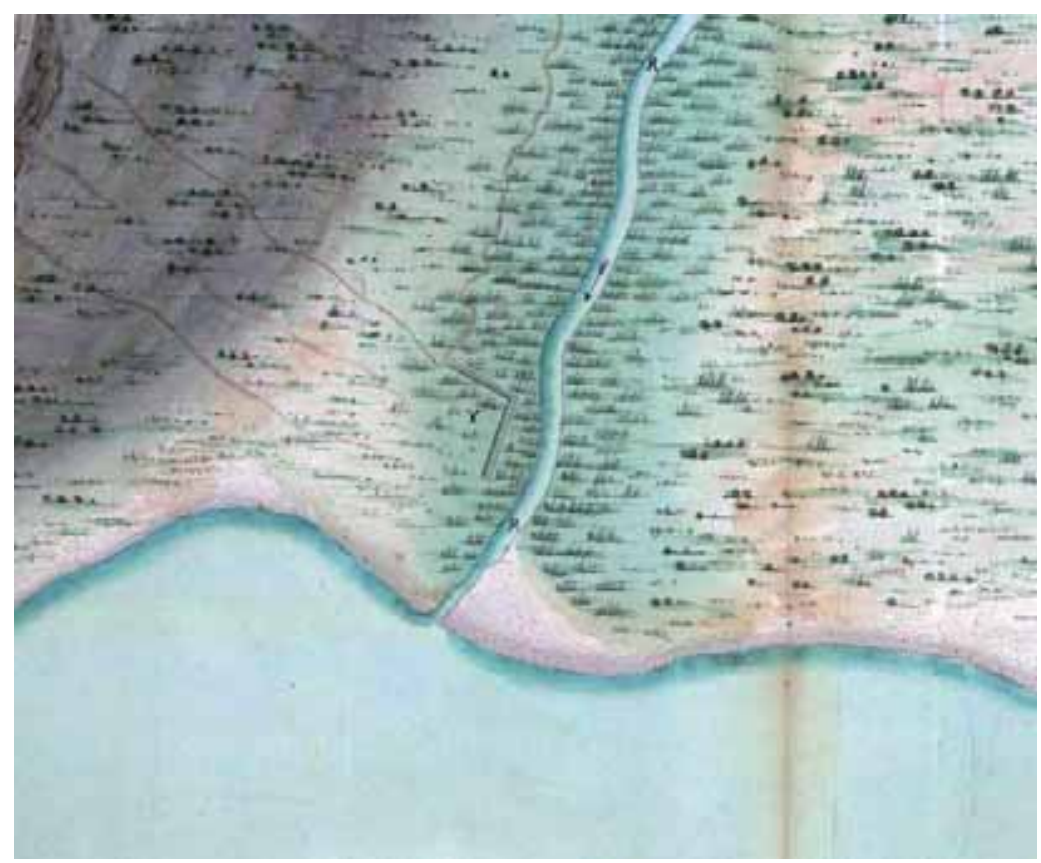

Fig. 4. Sector de un Plano y perfiles del pequeño Fuerte que se propone construir para la seguridad de los huertos de la Plaza de Melilla, 1752.

Su uso en la cartografía ${ }^{25}$ se realiza mayoritariamente durante el siglo XVIII, pero se puede ver todavía este nombre en algunos planos del siglo XIX. Ejemplos:

- Plano y perfiles del pequeño Fuerte que se propone construir para la seguridad de los huertos de la Plaza de Melilla, 1752, Joseph Gandon, AGS, signatura: MPD, 65, 066.

- Plano de Melilla con los Ataques de los Moros, 1729, AGS, signatura: MPD, 59, 066.

${ }^{25}$ BRAVO NIETO, Antonio, Cartografía Histórica de Melilla, Ciudad Autónoma de Melilla, V Centenario de Melilla, S.A, 1996. 
- Plano de la Plaza de Melilla y sus fortificaciones exteriores ${ }^{26}, 1761$, Gregorio Espinosa de los Monteros, Servicio Geográfico del Ejército (SGE) $n^{\circ} .149$.

- Plano del Presidio de Melilla y costa de África confinante ${ }^{27}, 1764$, Matheo Vodopich, SHM nº 4.688/7, C-32-14/MEL -G2/7.

- Plano de la plaza de Melilla en la costa de África con las cercanías que comprehenden las baterías y trincheras del exército ${ }^{28}$...., 1775, Juan Cavallero, SHM n ${ }^{\circ} .4696$, D-1 - 2/ MEL-GS/2.

- Plano de la última posición que ocupó el enemigo en las cercanías de esta plaza, 1775, Juan Cavallero, AGS, signatura: MPD, 24, 064.

- Plano de la Plaza de Melilla, 1775, Alexandro Fernion ${ }^{29}$.

- Plano de las inmediaciones de la Plaza de Melilla y Plano de la ciudad, plaza y fuerzas de Melilla ${ }^{30}$,Tomás López, 1793, Museo Naval (MN), signatura: 99-6.

- Plano que manifiesta el surgidero o abrigo de la Plaza de Melilla ${ }^{31}$. Finales del siglo XVIII, signatura: MNm. 911 (1 ), MN 99-8, Melilla (Ciudad) Cartas Náuticas.

- Plano de la Colonización en Melilla, 1883-1890, Archivo Intermedio de Melilla (AIM).

- Plano de Melilla y su campo, y plano de los contornos de Melilla con los límites que convendría adquirir ${ }^{32}$, sin autor, 1893, SGE n ${ }^{\circ} 179$.

- Plano del campo de Melilla y croquis de sus contornos, formado con los datos conocidos hasta hoy, 1893, Eduardo Lucini, publicado por La Ilustración Española y Americana.

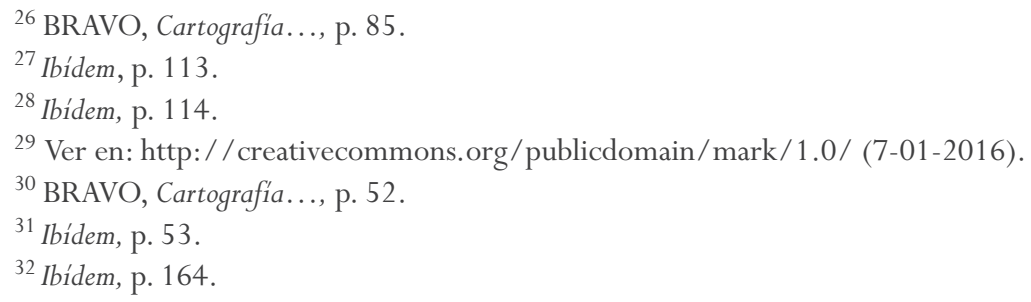


Río Oro. Se utiliza de manera puntual en algún plano del siglo XVIII y más abundantemente en el siglo XIX, para casi desaparecer a lo largo del XX. Ejemplos [5]:

- Plano de la Plaza de Melilla y su Campo hasta el alcance del Cañón, 1846, Francisco de Alvear, Nicolás Arespacochaga y Manuel Sevilla ${ }^{33}$.

- Plano de la Costa de África, entre la Bahía de Alhucemas y el cabo del Agua, sacado del publicado en 1857 por el Depósito Francés de Cartas y planos de la Mari$n a^{34}, 1867$, SGE $n^{\circ} .160$.

- Plano del campo fronterizo de Melilla levantado durante las acciones de guerra $^{35}$ del 25 y 26 de noviembre de 1855, SGE n .158.

- Plano de terreno contiguo a la Plaza de Melilla levantado con la brújula por el Capitán del Cuerpo Don José María Piñar durante las salidas que efectuó la guarnición.....1862, mde.es.

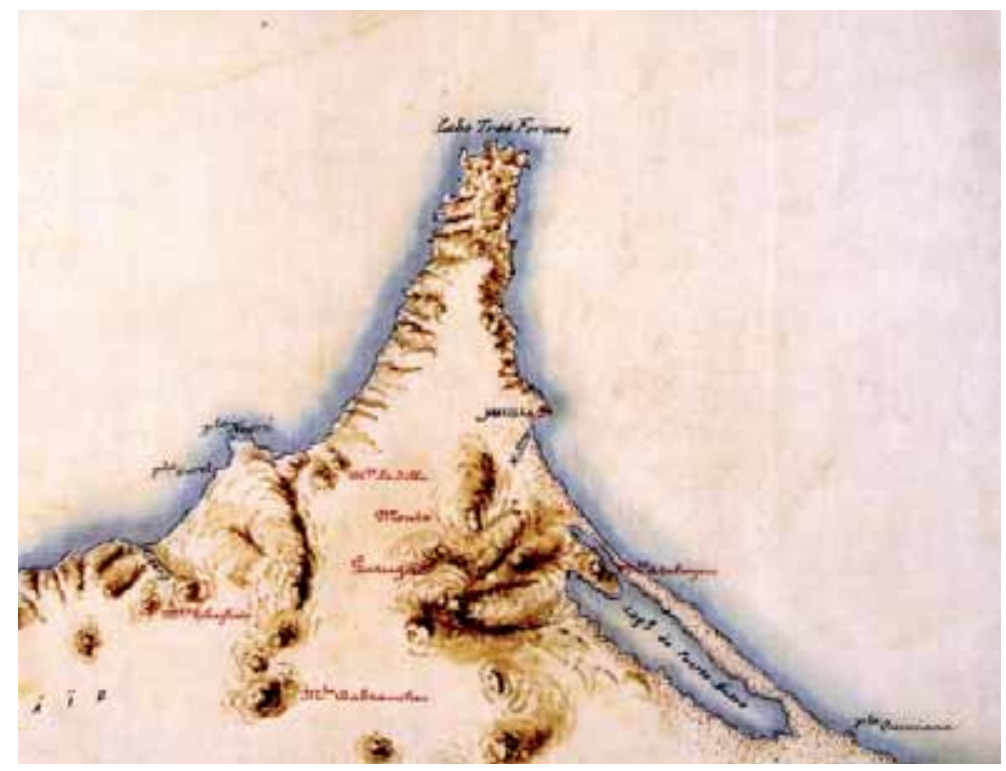

Fig. 5. Sector de un Plano de la Costa de África, entre la Bahía de Alhucemas y el cabo del Agua, 1857.

33 Ver en: http: / / catalogo.bne.es/uhtbin/cgisirsi/0/x/0/05?searchdata1=bica0000076799 (7-01-2016).

${ }^{34}$ BRAVO, Cartografía..., p. 166.

${ }^{35}$ Ibídem, p. 161. 
- Croquis del Terreno comprendido en los nuevos límites de Melilla, 1862, José María Pillar ${ }^{36}$, SGE nº 163.

- Anteproyecto de desviación del río Oro ${ }^{37}, 1863$, Francisco Arajol y de Solá, Melilla, SHM, signatura: nº 47 10/ 6, D- 1-16/ MEL-65/19.

- Plano del Campo Exterior de Melilla ${ }^{38}, 1890$, Alberto Suárez, SGE $\mathrm{n}^{\mathrm{o}} \cdot 171$.

- Plano de la plaza de Melilla y su campo exterior con el polígono de límites 39 demarcado en abril de 1891, Eligio Sousa y Juan Picasso, Archivo General de la Administración (AGA), África, Fondo Histórico de Marruecos, Caja 201, AGA M., expediente $n^{\circ} .2$.

- Croquis de Melilla y alrededores con el Gurugú y Mar Chica ${ }^{40}, 1893$, Francisco Galbis, SGE nº 178.

- Melilla y sus alrededores ${ }^{41}, 1893$, La Correspondencia de España, SGE nº . 181 .

Río de Oro. En 1722 Nicolás Vázquez ${ }^{42}$ lo llamaba con este nombre: “según las relaciones antiguas que se hallan en los Archivos de esta Plaza se ve que esta ciudad era grande población antes de su conquista, como también su comercio con las Costas de Levante por ser su situazion apropósito para ello y gozar de un clima mui benigno con el beneficio de un río de llamado comúnmente de Oro, el cual fecunda y riega toda la campaña, aunque no sea muy caudaloso" [6].

$\mathrm{Su}$ primera mención en la cartografía se produce en el siglo XVIII, pero es a partir de 1893 cuando comenzará a desplazar a las otras denominaciones. Ejemplos:

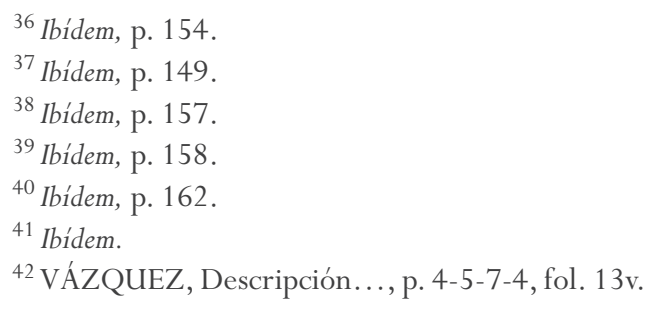




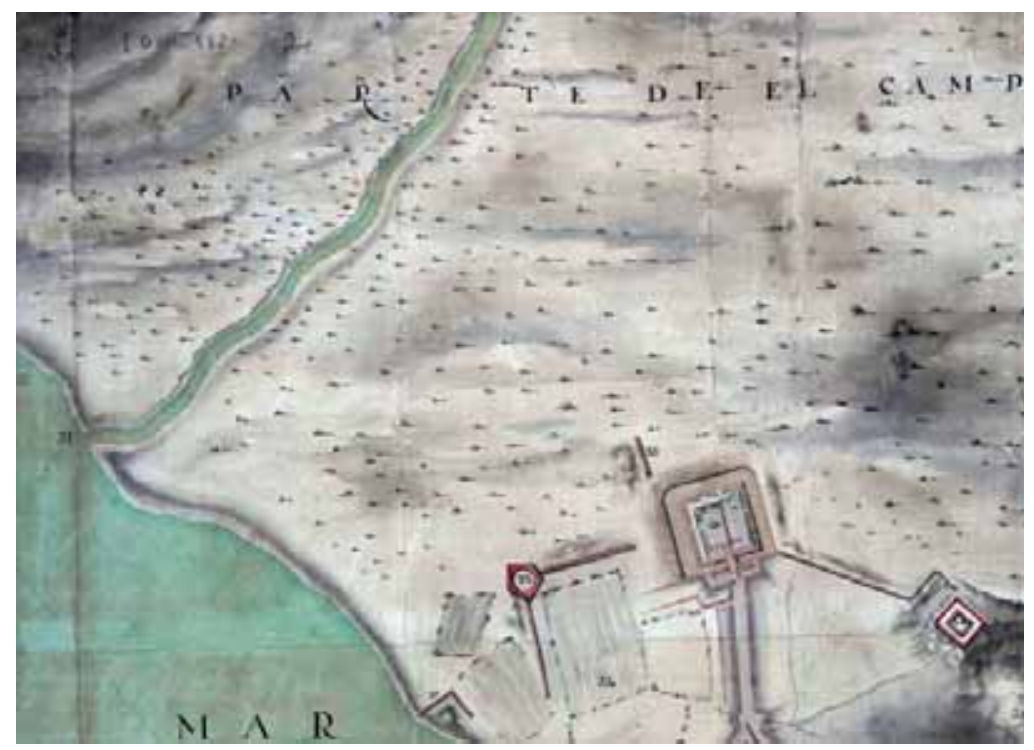

Fig. 6. Sector de un Plano de la Plaza de Melilla, sus fortificaciones y parte del Campo del Moro, 1774.

- Plano de la plaza de Melilla, 1758, SHM nº . 4713/12, D- 1- 19/ MEL $-\mathrm{G} 4 / 8^{43}$.

- Plano de la Plaza de Melilla, sus fortificaciones y parte del Campo del Moro, 1774, autor; Gregorio Sevilla, AGS, signatura: MPD, 21,062.

- Plano de Melilla y Campo Enemigo levantado con la plancheta por ${ }^{44}$...., 1849, Rafael Pallete y Puyol, SGE nº 156.

- Plano de Melilla y su campo, y plano de los contornos de Melilla con los límites que convendría adquirir, Francisco Coello, El Imparcial, octubre de 1893.

- Plano del Campo Exterior de la Plaza de Melilla ${ }^{45}$, 1894, Jesús Coloma, Francisco Fernández, Luis López y Ramón Moreno, SGE nº 184.

- Plano de Melilla, 1905, Memoria Junta del Puerto de Melilla, Archivo Autoridad Portuaria de Melilla (AAPM).

\footnotetext{
${ }^{43}$ BRAVO, Cartografía..., p. 112.

${ }^{44}$ Ibídem, p. 120.

${ }^{45}$ Ibídem, p. 173.
} 
- Plano de Melilla y parte del territorio ocupado en los años 1909 y 1910, mde.es.

- Croquis del teatro de operaciones en Melilla ${ }^{46}$. Cuerpo de Estado Mayor, Campaña de 1909, SHM nº 47 13/ 5, C- 1- 19/ MEL-G4/15.

- Anteproyecto de Urbanización y ensanche de Melilla, Croquis de Conjunto, 1910, Archivo Central de la Ciudad Autónoma de Melilla (ACCAM).

- Guía Calendario de Melilla, 1914, Melilla, Imprenta y Papelería La Española.

- Plano de terrenos concedidos al Ramo de Guerra, 1926, AAPM.

- Anteproyecto de desviación del río de Oro, 1935, AAPM nº 212.

Desde finales del siglo XVIII hasta principios del siglo XX en los documentos y proyectos oficiales se alternan los nombres de río del Oro y río Oro, este último predominante hasta finales del XIX, y río de Oro que se vuelve a usar a partir de 1846. Los tres nombres se usarán hasta casi desaparecer el primero a partir de 1920, consolidándose, poco a poco, el topónimo río de Oro en la administración militar y civil.

Las citas al río en la prensa nacional se remontan al año 1848 utilizando el nombre de río Oro (y en menor medida los otros dos) hasta la Campaña de 1893 en la que empieza a extenderse río de Oro. La prensa local y el lenguaje popular seguirían usando indistintamente río Oro y río de Oro hasta bien entrado los años 60 del siglo XX para terminar consolidándose poco a poco por vía consuetudinaria el topónimo río de Oro, usado mayoritariamente en nuestros días [7].

Las tres formas de llamar al río tienen un mismo origen, que se recoge en las crónicas ${ }^{47}$ de los siglos XVIII, XIX y XX y que relaciona el topónimo con una tradición rifeña que narra la existencia de oro en sus arenas: "Haremos mención del conocido como río de Oro, por su importancia relativa a Melilla, y cuyo nombre es debido á haberse hallado el rico metal en sus arenas, si hemos

\footnotetext{
${ }^{46}$ Ibídem, pp. 176-177.

${ }^{47}$ GARCÍA FARIA. Pedro, "El viaje del Ministro de Fomento a las posesiones de África", Revista de Obras Públicas, 1910, 58, tomo I, pp. 152-154.
} 
de dar crédito a las referencias de la tradición rifeña", idea reforzada por "la analogía de edad, estructura y composición de la cadena rifeña con nuestro sistema penibético, en el que radican los hierros de Almería, las platas de Sierra Almagrera, los plomos de Sierra de Gador, el oro de Granada" ${ }^{48}$.

El río, a pesar de su nombre, no arrastraba la menor partícula del codiciado metal ${ }^{49}$, no se habían encontrado pepitas en sus inmediaciones y los estudios e investigaciones pusieron de manifiesto que las arenas del río de Oro no eran auríferas. No obstante, a mediados del siglo XX, la leyenda aun pervivía y era alimentada por la fantasía y la especulación sobre la existencia de grandes riquezas mineras ${ }^{50}$. En 1910 El Heraldo militar ${ }^{51}$ afirmaba que en Melilla, "se ha presentado una denuncia de una mina de oro que radica en el Gurugú y ha sido descubierta por un excursionista que, días antes, visitó el famoso monte. Hallándose aquél en uno de los barrancos que desembocan en el valle del río Oro, vio una gruta y hacia ella se dirigió, llamando su atención las piedras que orlaban la entrada. En un principio creyó que se trataba de mineral de cobre, pero su sorpresa fue grande al convencerse de que se trataba de una mina de oro. Siguió su examen, hallando a pocos metros, entre las aguas de un yacimiento que allí había, una hermosa pepita. El descubridor, hombre inteligente, ha telegrafiado al Ministerio de Estado y al Majzen, para alegar en su día derechos de propiedad, que cree no podrá disputarle nadie, puesto que el Roghi concedió a la Sociedad Española Minas del Rif todas las de hierro de Guelaya, pero no las de otros metales".

Ginés San Martín ${ }^{52}$, más recientemente, afirmaba que la existencia de oro en el monte Gurugú había estado presente en diferentes épocas, esti-

${ }^{48}$ FERNÁNDEZ NAVARRO, Luis, Estudios geológicos en el Rif oriental memorias de la Real Sociedad Española de Historia Natural, tomo VIII, 1911, pp. 5-61.

${ }^{49}$ FERNÁNDEZ NAVARRO. LUCAS, "Minerales del Norte de Marruecos", África Española, $\mathrm{n}^{\circ} .18,1914$, p. 284.

${ }^{50}$ El diario Pabellón Nacional, de 29 de octubre de 1975 se refiere al monte Gurugú, como Monte de Oro y el semanario Archivo Diplomático-Político, 7 de agosto de 1883, se habla de la conveniencia de ocupar la posición de Cabrerizas para dominar todo el extenso valle de Frajana y Mazuza, por donde corre el oro".

51 "Oro en el Gurugú", El Heraldo militar, de 14 de marzo de 1910, p.2.

52 SAN MARTíN SOLANO, Ginés, "La Compañía Española de Minas del Rif (1907-1984)”, Aldaba, Revista del Centro Asociado a la UNED de Melilla, nº. 5, 1985, pp. 55-69. 
mando que en esa creencia podía estar el origen del nombre del río, pues las leyendas que llamaron la atención de los buscadores de oro (siglo XIX) eran posteriores al topónimo río de Oro. Ahora bien, la leyenda era muy antigua y Madoz en su Diccionario Geográfico-Estadístico-Histórico de España y sus posesiones de ultramar ${ }^{53}$, recogiendo trabajos anteriores ${ }^{54}$, decía que fue "esta ciudad en lo antiguo muy populosa con 10.000 casas dentro de sus muros, en donde residía su señor, cuya jurisdicción era dilatada. Se empleaban sus moradores en el comercio de oro e hierro, cultivando sus ricas minas y se pescaban perlas en su cala”.

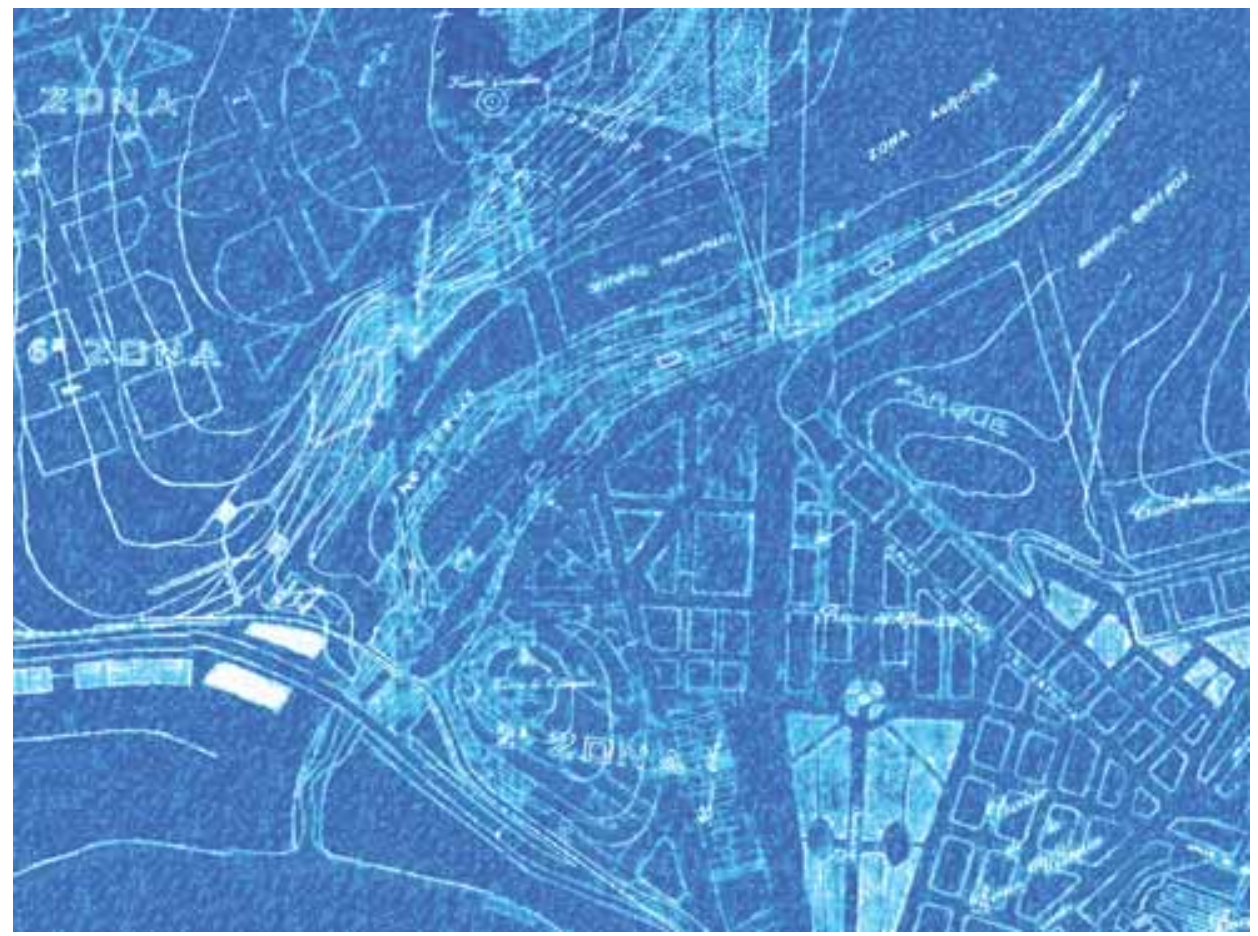

Fig. 7. Sector del Anteproyecto de Urbanización y ensanche de Melilla, Croquis de Conjunto, 1910.

${ }^{53}$ MADOZ, Pascual, Diccionario Geográfico-Estadístico-Histórico de España y sus posesiones de ultramar, (Madrid, 1845-1850), volumen XI, p. 362.

${ }^{54}$ En efecto, Madoz reproduce lo recogido por ESTRADA, Población General de España..., p. 544 que a su vez toma estos datos de MARMOL CARVAJAL, Luis de, Descripción general de África, 1573, volumen 2, lib. 4, Fol. 52, Cap. 91. 
El monte, nos recuerda San Martín ${ }^{55}$, volvió a llamar la atención de los buscadores de oro y en el año 1932 se concedieron dos "Permisos de Investigación” para el reconocimiento de unos filones auríferos, solicitados por una sociedad constituida en Melilla en el año 1932, denominada La Aurífera del Rif, S. A., a pesar de la inexistencia de los ricos yacimientos de metales preciosos sobre los que tanto se había fabulado. No obstante, nos dice que con posterioridad (años 1952-1954) se volvieron a realizar reconocimientos que evidenciaron "la existencia real de unos afloramientos auríferos localizados en los altos del Monte Gurugú, filones ignorados por el común de la gente, que habían sido investigados en varias ocasiones” y que un informe del Laboratorio del Instituto Geológico (Madrid) había evidenciado la existencia de oro, pero el yacimiento tenía un escaso interés comercial, por razón de su baja ley de metal, cuantificada por «indicios auríferos».

En la literatura contemporánea, Pedro Luis de Gálvez ${ }^{56}$ parece "sugerir" una respuesta al topónimo río de Oro en la trágica "leyenda africana" que relata en su novela corta El oro del río, en la que David, un anciano mercader judío y rifeño, al ver flotando en las aguas la rubia cabellera de su hija Jasiva, como un disco de oro que arrastraba la corriente hacia el mar, pedía a grandes voces que le rescatasen aquel oro que le había sido robado ${ }^{57}$ de sus arcas. ¡Yo daré un dracma y otros dos, al que me traiga el oro del río! [8]

Entorno a estas ideas y leyendas está el origen del topónimo río de Oro, el cual también serviría de inspiración a muchos empresarios a lo largo del siglo XX para dar nombre a sus comercios: La Bola de Oro, El Marco de Oro, El Barco de Oro, El León de Oro, La Pluma de Oro, El Clavel de Oro, El Corazón del Oro, La Espiga de Oro, La Lluvia de Oro, La Llave de Oro, El Pedal de Oro, El Doblón de Oro, etc.

${ }^{55}$ SAN MARTíN SOLANO, Ginés, "El Río de Oro”, Melilla Hoy, de 6 de febrero de 2000.

${ }^{56}$ LUIS DE GÁLVEZ, Pedro, "El oro del río. Leyenda africana”, Hojas Selectas, nº. 181, 1917, pp. 163-166. Ver en: http:// hemerotecadigital.bne.es $/$ issue. vm?id $=0001437743$ \&page $=163$ \&search $=$ MELILLA + ORO\&lang $=$ es.

${ }^{57}$ En la leyenda Jasiva había permanecido cautiva por su propio padre, hasta que su amante Isacar, la liberó “y no pudiendo huir, precipitáronse juntos en el río”. 
Al fin al cabo, durante un tiempo, Melilla, la Bilbao del Mediterráneo, presumió de ser una ciudad de oro.

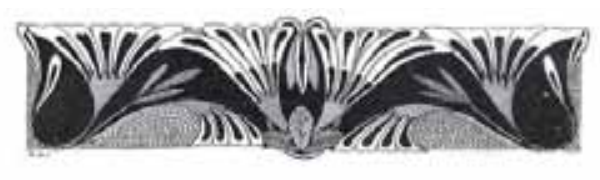

\section{EL ORO DEL RIO}

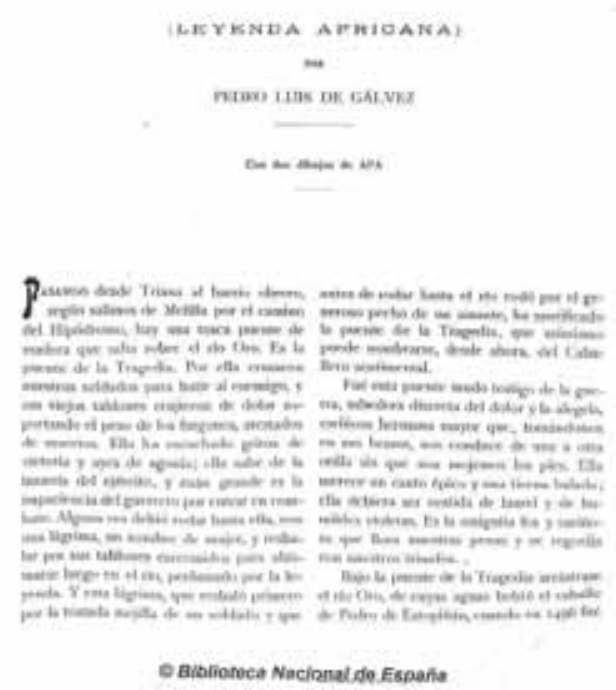

Fig. 8. "El oro del río. Leyenda africana”, Hojas Selectas, 1917.

\section{Fuentes documentales}

Archivo General de la Administración (AGA)

Archivo Central de la Ciudad Autónoma de Melilla (ACCAM)

Archivo General de Simancas (AGS)

Archivo Intermedio de Melilla (AIM)

Archivo Autoridad Portuaria de Melilla (AAPM)

Biblioteca Digital. Biblioteca Nacional de España (B

Biblioteca Digital Hispánica

Biblioteca Virtual del Ministerio de Defensa

Europeana Collections

Portal Europeo de Archivos

Servicio Geográfico del Ejército (AGE)

Servicio Histórico Militar (SHM) 